\title{
Ruptured mitral-aortic intervalvular fibrosa aneurysm with flail aortic valve
}

\author{
Arunkumar Panneerselvam, ${ }^{1}$ Panneerselvam Subbiahnadar ${ }^{2}$ \\ ${ }^{1}$ Cardiology Department, Eugene Clinic, Mettupalayam, India; \\ ${ }^{2}$ Department of Family medicine, Eugene Clinic, Mettupalayam, India
}

Correspondence to Dr Arunkumar Panneerselvam, drparun1976@gmail.com

\section{DESCRIPTION}

Rupture of mitral-aortic intervalvular fibrosa aneurysm is a rare complication of aortic valve endocarditis. ${ }^{1}$ A 43 -yearold man presented with persistent fever and progressive dyspnoea of 3 months duration. On admission, he was in florid pulmonary oedema and clinical examination showed findings of severe aortic regurgitation. His electrocardiogram revealed complete heart block with junctional escape rhythm. The echocardiogram showed an aneurysm of mitral-aortic intervalvular fibrosa in parasternal long-axis view (figure 1 and video 1). Such aneurysms are recognised echocardiographically as an echo-lucent space in the mitral-aortic intervalvular fibrosa in the parasternal longaxis and short-axis views. The non-coronary cusp of the aortic valve was flail and colour Doppler echocardiography demonstrated rupture of the aneurysm with communication to both left ventricular outflow tract and left atrium.
There was severe aortic regurgitation with mild mitral regurgitation. The short axis view revealed large vegetation attached to the non-coronary cusp of aortic valve with root abscess formation (figure 2 and video 2). He died due to refractory heart failure. This case illustrates possible complications of aortic valve endocarditis flail leaflet, severe aortic regurgitation, rupture of intervalvar fibrosa aneurysm, root abscess and complete heart block.

Video 1 Parasternal long-axis view demonstrating the aneurysm in the mitral-aortic intervalvular fibrosa. Colour Doppler across LVOT reveals pulsatile nature of the aneurysm with communication to both LVOT and left atrium. The severe aortic regurgitation can also be seen with flail aortic valve cusp.

Video 2 Parasternal short-axis view showing large vegetation attached to the non-coronary cusp of the aortic valve with root abscess in the 12' o clock position.

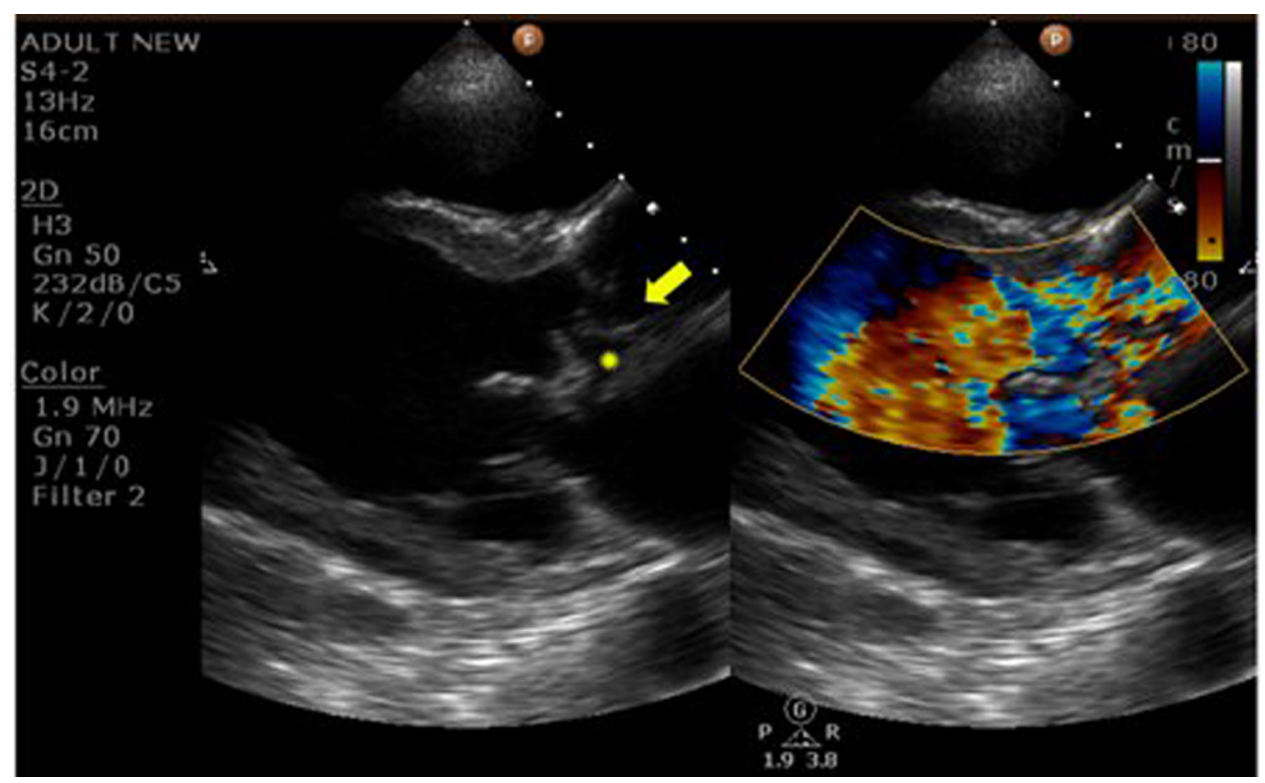

Figure 1 Parasternal long-axis view demonstrating the aneurysm in the mitral-aortic intervalvular fibrosa $\left({ }^{*}\right)$. Colour Doppler across left ventricular outflow tract (LVOT) reveals pulsatile nature of the aneurysm with communication to both LVOT and left atrium. The flail noncoronary cusp (indicated by arrow) with severe aortic regurgitation can also be seen. 


\section{BMJ Case Reports}

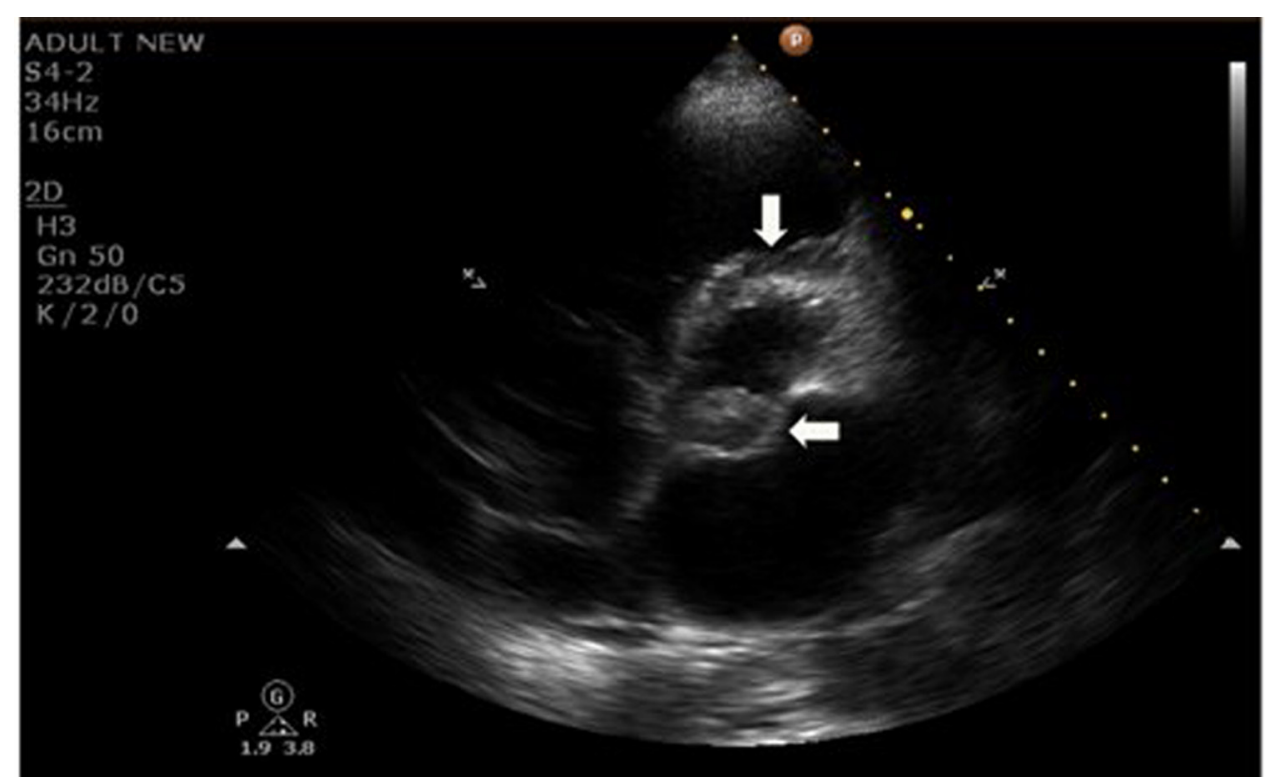

Figure 2 Parasternal short-axis view showing large vegetation (horizontal arrow) attached to the non-coronary cusp of the aortic valve with root abscess in the 12' o clock position (vertical arrow).

\section{Competing interests None.}

Patient consent Obtained.

\section{REFERENCES}

1. Bansal RC, Graham BM, Jutzy KR, et al. Left ventricular outflow tract to left atrial communication secondary to rupture of mitral-aortic intervalvular fibrosa in infective endocarditis: diagnosis by transesophageal echocardiography and color flow imaging. J Am Coll Cardiol 1990;15:499-504.

This pdf has been created automatically from the final edited text and images.

Copyright 2011 BMJ Publishing Group. All rights reserved. For permission to reuse any of this content visit http://group.bmj.com/group/rights-licensing/permissions.

BMJ Case Report Fellows may re-use this article for personal use and teaching without any further permission.

Please cite this article as follows (you will need to access the article online to obtain the date of publication).

Panneerselvam A, Subbiahnadar P. Ruptured mitral-aortic intervalvular fibrosa aneurysm with flail aortic valve. BMJ Case Reports 2011;

10.1136/bcr.06.2011.4416, date of publication

Become a Fellow of BMJ Case Reports today and you can:

- Submit as many cases as you like

- Enjoy fast sympathetic peer review and rapid publication of accepted articles

- Access all the published articles

- Re-use any of the published material for personal use and teaching without further permission

For information on Institutional Fellowships contact consortiasales@bmjgroup.com

Visit casereports.bmj.com for more articles like this and to become a Fellow 